\title{
Controle social no Sistema Único de Saúde: subsídios para construção de competências dos conselheiros de saúde*
}

\author{
| ${ }^{1}$ Rosângela Minardi Mitre Cotta, ${ }^{2}$ Mariana de Melo Cazal, ${ }^{3}$ Jôsi Fernandes \\ de Castro Rodrigues, ${ }^{4}$ Karine de Oliveira Gomes, ${ }^{5}$ Túlio da Silva Junqueira I
}

Resumo: Este artigo discute a experiência do curso de capacitação de conselheiros de saúde do município de Viçosa-MG, com base na perspectiva de sensibilização para o exercício consciente do controle social, possibilitando assim a construção de um sistema de saúde mais justo e igualitário, segundo o ideal pensado pelo movimento da reforma sanitária brasileira. Realiza uma abordagem qualitativa sobre as dinâmicas apresentadas no curso, sendo este baseado na metodologia ativa de ensino-aprendizagem. A metodologia participativa e a utilização de estratégias que privilegiaram a sistematização do conteúdo, assim como a reflexão sobre os referenciais teóricos, apresentados a partir da correlação dos temas com as experiências práticas, foram fundamentais para ampliar e aprofundar o processo de empoderamento dos conselheiros. Como resultado, foi possível identificar alguns desafios para o exercício do controle social, como a importância da participação ativa e da necessidade de buscar informaçōes e trocar experiências. Destarte, destaca-se que a participação dos conselheiros de saúde em oficinas de capacitação aparece como uma possibilidade de superação das dificuldades de implementação das conquistas legais, ao sensibilizar estes atores sociais para transpor a posição de meros expectadores passivos em protagonistas na construção de um sistema de saúde universal e equitativo.

\author{
1 Doutora em Saúde \\ Pública pela Universidade \\ de Valencia, Espanha. \\ Professora Adjunta - Área \\ Política Públicas de Saúde, \\ Departamento de Nutrição e \\ Saúde - Universidade Federal \\ de Viçosa (UFV), Viçosa, MG \\ Coordenadora/Orientadora. \\ Endereço eletrônico: \\ rmmitre@ufv.br \\ ${ }^{2}$ Mestranda em Ciências da \\ Nutrição - Universidade Federal \\ de Viçosa, Departamento \\ de Nutrição e Saúde (UFV) \\ Viçosa, MG \\ ${ }^{3}$ Graduada em Nutrição e Saúde \\ - Universidade Federal de Viçosa, \\ Departamento de Nutrição e \\ Saúde (UFV), Viçosa, MG. \\ ${ }^{4}$ Mestre em Ciências da \\ Nutrição pela Universidade \\ Federal de Viçosa. Professora \\ Auxiliar do Instituto \\ Multidisciplinar em Saúde, \\ Campus Anísio Teixeira, \\ Universidade Federal da Bahia \\ gUFB0, Bahia, BA \\ ${ }^{5}$ Mestre em Administração \\ Pública. Doutorando em \\ Ciências de Nutrição - \\ Universidade Federal de \\ Viçosa,Viçosa, MG. Professor da \\ UNIFESO, Teresópolis, RJ
} social, conselho de saúde, controle social, metodologia ativa. 


\section{Introdução}

A perspectiva para o desenvolvimento de várias formas de participação social ocorreu com o processo de redemocratização iniciado no período populista, trazendo de volta a disputa político-partidária e a revitalização sindical. Contudo, foi na década de 1980, marcada pelo início do fim do regime ditatorial, que ocorreu a pluralização dos movimentos sociais, passando a abranger várias novas temáticas, como a questão das mulheres, dos negros, de crianças, dos índios, do meio ambiente, entre outros (SOARES do BEM, 2006). Essa participação social deve ser entendida como o exercício de uma capacidade organizativa concreta da população, tendo em vista o controle sobre atividades públicas a partir da ativação da sociedade civil com a presença da população na arena política em defesa de seus interesses (MENDES, 2006).

Ao fim da ditadura militar, através do fortalecimento da sociedade civil, no período entre 1985 e 1988, originou o amplo movimento pela Constituinte, responsável pela nova Carta Constitucional (1988), que introduziu vários dispositivos centrados na garantia de direitos sociais (SOARES do BEM, 2006).

Conforme a Constituição Federal de 1988, o Sistema Único de Saúde (SUS) foi instituído e organizado de acordo com as seguintes diretrizes: descentralização, atendimento integral com prioridade para as atividades preventivas e participação da comunidade (BRASIL, 2003, p. 25). Esta regulação constitucional do SUS se completa em 1990, com a edição das leis no 8.080 e 8.142 .

A Lei $n^{\circ}$ 8.080, de 19 de setembro de 1990, instituiu o SUS obedecendo a princípios doutrinários e operacionais, tais como: universalidade de acesso aos serviços de saúde em todos os níveis de assistência, integralidade de assistência, equidade, descentralização político- administrativa, regionalização e hierarquização e participação da comunidade (BRASIL, 2003).

Através do exposto, pode ser percebido que, com o SUS, a saúde emerge como questão de cidadania e a participação política como condição de seu exercício, perspectiva esta assegurada no princípio constitucional de "participação da comunidade" (GUIZARDI; PINHEIRO, 2006). Por conseguinte, a perspectiva a ser adotada para a participação social será a de empowerment, ${ }^{1}$ ou perspectiva como fim. A participação social é definida como a possibilidade de indivíduos, e coletivos fortalecerem sua capacidade de percepção, opinarem e participarem 
efetivamente na implantação e gestão dos serviços públicos dos quais são beneficiados, através de um pensamento reflexivo e crítico sobre a realidade (CARVALHO, 2004).

A Lei $\mathrm{n}^{\circ}$ 8.142, de 28 de dezembro de 1990, dispõe sobre as transferências intergovernamentais de recursos financeiros na área de saúde e sobre a participação da comunidade na gestão do SUS (BRASIL, 2003). Desde então, os conselhos de saúde vêm sendo criados na maioria dos municípios brasileiros, com o intuito de se tornarem canais efetivos de participação da sociedade civil e inovar a gestão pública permitindo o exercício de uma cidadania ativa (GERSCHMAN, 2004). Os conselhos de saúde são considerados os principais órgãos de controle social na definição do sistema e dos serviços de saúde (WENDHAUSEN; CAPONI, 2002).

Soares e Trincaus (2007) apontam como pertinente aos conselhos de saúde, o papel de deliberar sobre a definição e monitoramento das políticas de saúde a serem implementadas, ou seja, exercer o controle social.

O Conselho de Saúde, em caráter permanente e deliberativo, é um órgão colegiado composto por representantes do governo, dos prestadores de serviço, profissionais de saúde e usuários e atua na formulação de estratégias e no controle da execução da política de saúde na instância correspondente, inclusive nos aspectos econômicos e financeiros, cujas decisões serão homologadas pelo chefe do poder legalmente constituído em cada esfera de governo (art. $1^{\circ}$, $\$ 2^{\circ}$, da Lei no 8.142/90).

Cunha (2003) assinala o controle social, como uma conquista da sociedade civil, devendo ser entendido como um instrumento e uma expressão da democracia. Busca-se com a democratização, eliminar as formas autoritárias e tradicionais de gestão das Políticas Sociais, bem como a adoção de práticas que favoreçam uma maior transparência das informaçooes e maior participação da sociedade no processo decisório (SILVA et al., 2007).

Segundo Imaginário (1998), o termo competência pode ser entendido a partir de duas perspectivas. Na primeira, desde um sentido mais amplo, a competência pode ser entendida como a capacidade de realizar uma tarefa num determinado contexto e transferir os conhecimentos que lhe estão subjacentes para outros contextos e tarefas. $\mathrm{Na}$ segunda perspectiva, entende-se competência a partir de um sentido mais específico, ou seja, como a capacidade de se realizar uma tarefa em particular em condiçôes peculiares e pormenorizadas com a exclusão dos conhecimentos e compreensão dos mecanismos que lhe estão associados. 
Considerando que a falta de um processo de formação pode constituir-se em recurso negativo para o empoderamento (WENDHAUSEN et al., 2006), tendo em vista que a educação permanece como um dos mais relevantes instrumentos para a garantia da passagem de um modelo de democracia representativa para aquele centrado no exercício ativo da cidadania (SOARES do BEM, 2006), o objetivo deste trabalho foi capacitar os Conselheiros Municipais de Saúde do município de Viçosa-MG, visando a sensibilizá-los para o exercício pleno e consciente de seu papel no controle social, possibilitando assim a construção de um sistema de saúde mais justo e igualitário.

\section{Metodologia}

Este trabalho foi realizado em resposta as necessidades de capacitação e empoderamento dos conselheiros municipais de saúde, detectadas pelo trabalho desenvolvido por Martins (2007) em sua dissertação de mestrado, que avaliou a experiência do controle social no Conselho Municipal de Saúde (CMS), e ainda verificou a percepção dos usuários do Programa Saúde da Família (PSF), sobre a implantação do SUS.

Em consonância com o disposto na Resolução no 196/96 do Conselho Nacional de Saúde, a pesquisa foi aprovada pelo Comitê de Ética em Pesquisa da Universidade Federal de Viçosa (Protocolo número Of. Ref. no 010/2006). Além disso, cumprindo com a orientação da necessidade de realização de estudo piloto para a verificação da eficiência do instrumento escolhido para a realização do trabalho (RICHARDSON et al., 1999), foi realizado um estudo piloto no município de Viçosa.

Assim, realizou-se o I Curso de Capacitação de Conselheiros Municipais de Saúde, intitulado "Controle social no Sistema Único de Saúde: subsídios para construção de competências dos Conselheiros de Saúde”, em outubro de 2007, no município de Viçosa-MG. As atividades desenvolvidas tiveram como objetivo principal fortalecer e qualificar o exercício da cidadania, conscientizando os conselheiros sobre sua função de representação de um grupo e ainda promover o reconhecimento do Conselho como lócus de manifestações de interesses plurais em busca do benefício de toda sociedade. O curso foi baseado na metodologia ativa de ensino-aprendizagem, uma vez que esta abordagem pedagógica se baseia 
no aumento da capacidade do sujeito em participar como agente de transformação social, durante o processo de detecção de problemas reais e de busca por soluções originais (BORDENAVE; PEREIRA, 2005; BORDENAVE, 1999).

Seguindo a orientação de Freire (2007), o processo ensino-aprendizagem utilizado baseou-se na problematização e no princípio da autonomia, considerando e respeitando a bagagem cultural e os saberes construídos na prática comunitária dos conselheiros, permitindo, com isso, a passagem da consciência ingênua para a consciência crítica.

Por meio da ficha de cadastro, preenchida pelos próprios participantes no início do curso, foi possível traçar o perfil do grupo. A mesma incluía os seguintes itens: nome, função no conselho, categoria que representa no CMS, participação em outras gestōes e conhecimento da importância de ser conselheiro de saúde.

O curso foi realizado a partir da explanação teórica de temas relacionados à saúde e ao controle social, seguidas de dinâmicas de grupo orientadas por questôes de aprendizagem que estimularam a discussão e análise crítica dos temas apresentados, permitindo a participação e a integração dos conselheiros, assim como o maior entendimento do referencial teórico trabalhado.

Para a realização das dinâmicas, os participantes foram divididos em dois grupos, segundo categoria de representação; além disso, foram utilizados materiais de apoio, como cartolinas brancas, pincéis atômicos, folhas de papel almaço pautadas, canetas, entre outros. Cada grupo foi acompanhado por um coordenador, que ficou encarregado de conduzir a discussão e incentivar a integração e participação de todos os conselheiros.

A problematização realizada nas dinâmicas a partir da exposição e discussão objetivou motivar o participante ao contato com as informações e à produção do conhecimento, sobretudo com a finalidade de solucionar os impasses e promover seu próprio desenvolvimento (MITRE et al., 2008). Ao perceber que a nova aprendizagem é um instrumento necessário e significativo para ampliar suas possibilidades e caminhos, esse poderá exercitar a liberdade e a autonomia na realização de escolhas e na tomada de decisões (CYRINO; TORALLESPEREIRA, 2004).

O primeiro tema abordado foi "Paradigmas da Saúde e Determinantes Sociais de Saúde", seguido da dinâmica "Discussão e Construção Coletiva de Cartaz". 
O cartaz foi escolhido por ser um recurso simples e eficiente para despertar o interesse e a curiosidade dos participantes (TURANO; ALMEIDA, 1999). Com base na fundamentação legal do direito à saúde, esta dinâmica foi orientada pelas perguntas "O que é saúde?" e "O que é preciso para ter saúde?", visando a promover a compreensão e reflexão dos participantes sobre o conceito de saúde como resultado das condições de vida, associada a seus determinantes políticos, econômicos e sociais.

A partir desta dinâmica, foi possível perceber o perfil de cada conselheiro de saúde e organizar a segunda dinâmica, o "Grupo de Verbalização e Grupo de Observação", para desenvolver a capacidade de observação, avaliação crítica, julgamento de ideias e desempenho, através da atuação dos participantes em dois níveis: observação e discussão (TURANO; ALMEIDA, 1999).

Inspirada no tema "Participação e controle social por meio do Conselho de Saúde", os grupos foram subdivididos em dois grupos: um grupo de verbalização (GV) e outro grupo de observação (GO), compostos com aproximadamente $50 \%$ do total dos participantes. Os grupos formaram dois círculos, de forma que o GV ficou disposto no centro da sala e o GO ficou em torno do GV, seguindo recomendação de Turano e Almeida (1999). Enquanto o GV discutiu a questão "Qual é o papel do Conselho de Saúde na participação e controle social", o GO ficou observando e anotando os pontos relevantes da discussão para participar em momento posterior. Em seguida, os dois grupos foram reunidos e os integrantes do GO verbalizaram suas considerações sobre os pontos discutidos pelo GV, sintetizando as discussōes da dinâmica com a construção de um cartaz.

A última dinâmica foi realizada após a explanação do tema "Controle Social: o SUS e a participação social na gestão da política de saúde" e consistiu num "Estudo dirigido" do Regimento Interno do Conselho Municipal de Viçosa, seguido de uma discussão orientada por perguntas relacionadas ao texto e da construção de cartazes apontando os pontos negativos que dificultavam o funcionamento do CMS, as perspectivas esperadas e quais os principais problemas que poderiam acontecer na gestão atual do CMS.

Esta técnica foi escolhida por permitir a reflexão, de forma cooperativa, a respeito de um assunto, explorando o conhecimento comum que o grupo possui dele, aplicando a imaginação construtiva e chegando à compreensão de um fato, às deliberaçôes e à conclusão de uma tarefa (TURANO; ALMEIDA, 1999). 
Resultados e discussão

Caracterização dos participantes

O curso contou com a participação de 29 conselheiros de saúde. Destes, a maioria era titular $(55,2 \%)$ e não havia participado como membro do conselho em outra gestão $(62,1 \%)$ (tabela 1$)$.

Tabela 1. Caracterização dos conselheiros municipais de saúde segundo função, categoria de representação e experiência no Consellho- Viçosa-MG (2007)

\begin{tabular}{|l|c|c|}
\hline Variáveis & N & \% \\
\hline Função & 16 & 55,2 \\
Titular & 7 & 24,1 \\
Suplente & 6 & 20,7 \\
Conselheiro de Bairro & & \\
\hline Categorias de representação & 0 & 0 \\
Governo Municipal & 3 & 10,4 \\
Prestadores de Serviço & 5 & 17,2 \\
Profissionais de Saúde & 15 & 51,7 \\
Usuários & 6 & 20,7 \\
Conselheiros de Bairro & & \\
\hline Participação em outra gestão & 11 & 37,9 \\
Sim & 18 & 62,1 \\
Não & 29 & 100 \\
\hline Total & 29 & \\
\hline
\end{tabular}

Pela tabela 1, pode-se visualizar que não houve representação do governo municipal no curso. Este fato pode refletir o medo da "partilha de poder", uma vez que por estarem em jogo diferentes concepçōes e projetos políticos, o Poder Executivo cria estratégias para não discutir algumas questôes, evitando assim o envolvimento dos conselheiros na participação efetiva das decisões (GERSHMAN, 2004). Labra (2002) sugere a necessidade de se repensar o processo democrático como um todo, necessitando de transformações não só nas regras do jogo, destinadas a assegurar a representação e a participação política dos cidadãos; mas também destaca a necessidade de se reformar a lógica política para sustentar este processo democrático, de modo que os conselhos de saúde, que já foram outrora 
regulamentados legalmente, sejam realmente reconhecidos pelas elites políticas como espaços para interferirem efetivamente na transformação do sistema sanitário.

Por outro lado, a maioria $(51,7 \%)$ dos participantes no curso era representante dos usuários do SUS. Segundo Cortes (2002), as organizações que representam os interesses dos usuários cada vez mais têm renovado esforços para aumentar sua influência nos Conselhos de Saúde. Além disso, os representantes dos usuários parecem reconhecer que, com a Constituição Federal de 1988, foi aberta a possibilidade de participação dos usuários no processo de decisão da política setorial, aumentando o interesse pelo assunto.

Em relação à importância do conselheiro: a maioria dos participantes (48,3\%) considerou o fato de poder contribuir, planejar e controlar as Políticas de Saúde para a melhoria da qualidade de vida das pessoas; enquanto $31,0 \%$ consideraram o fato de conhecer, interferir e ter poder de decisão na política de saúde; enquanto o restante $(20,6 \%)$ afirmou que a importância de ser conselheiro é poder conhecer e promover a melhoria da situação de saúde do município (10,3\%) e apenas $10,3 \%$ relataram que era por promover o controle social.

Corroborando Gerschman (2004), este resultado indica que poucos entrevistados atribuem ao conselho o papel de viabilizar o controle social, mesmo se tratando de um atributo essencial deste órgão idealizado pelo movimento social em saúde e garantido pela Lei ${ }^{\circ}$ 8142. Esta dificuldade pode ser atribuída à falta de preparo dos conselheiros e ao desconhecimento de sua função (WENDHAUSEN; CAPONI, 2002), justificando a necessidade de capacitaçóes permanentes para que eles possam conhecer seu papel e aprofundar as discussões na formulação e implantação das políticas municipais de saúde (SOARES; TRINCAUS, 2007).

\section{Dinâmicas}

\section{Discussão e construção coletiva de cartaz}

As figuras 1 e 2 apresentam os cartazes confeccionados pelos conselheiros em relação aos temas "O que é saúde?” e "O que é preciso para ter saúde”. As primeiras tentativas sistemáticas de construir teoricamente o conceito de saúde partiram da noção de saúde como ausência de doença (BOURSE, 1975). Neste conceito, é possível perceber a concepção do homem reduzida a um corpo circunscrito à sua 
dimensão biológica, prevalecendo a ideia de corpo como "máquina" podendo ser montada e desmontada a qualquer "defeito", excluindo-se as dimensões relacionais, psíquicas e afetivas (BOSI; MERCADO, 2004).

Em 1948, a Organização Mundial da Saúde (OMS) ampliou este conceito, definindo que "Saúde é o estado de completo bem-estar físico, mental e social, e não meramente a ausência de doença ou incapacidade" (CALLAHAN, 1973). Este conceito incorpora dois aspectos: o primeiro avança na concepção da saúde ao definir que saúde não é meramente a ausência de doença, que transcende as concepções que tendem a reduzir os problemas sanitários ao âmbito das doenças e dos serviços de saúde hospitalocêntricos, mas o segundo aspecto torna este conceito ultrapassado, ao considerar uma perfeição inatingível, atentando-se às próprias características da personalidade (FERRAZ, 1997).

Nossos resultados corroboram o conceito de saúde da Organização Panamericana de saúde (OPAS), segundo a qual saúde deve ser entendida como resultado do estilo de vida, condições biológicas e acesso aos bens e serviços (OPAS, 2002).

Figura 1. Cartaz do Grupo 1: “O que é saúde”. Viçosa-MG (2007)

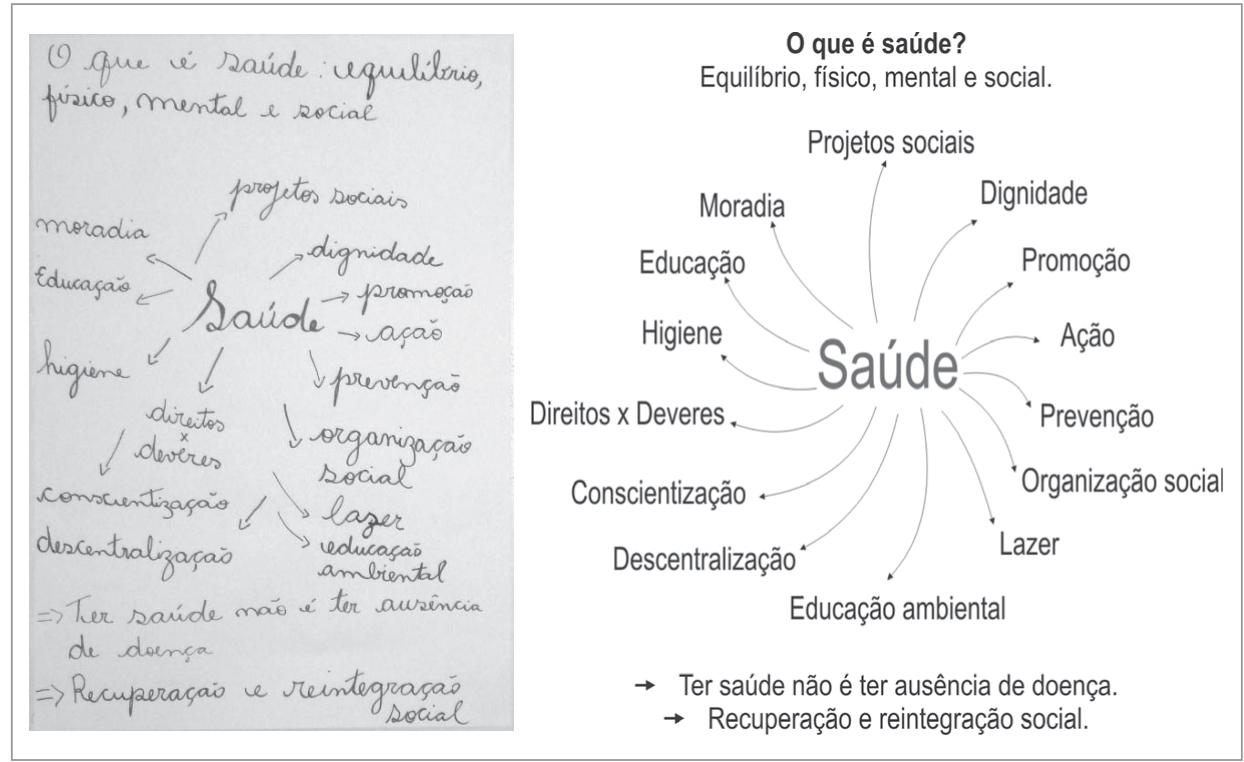



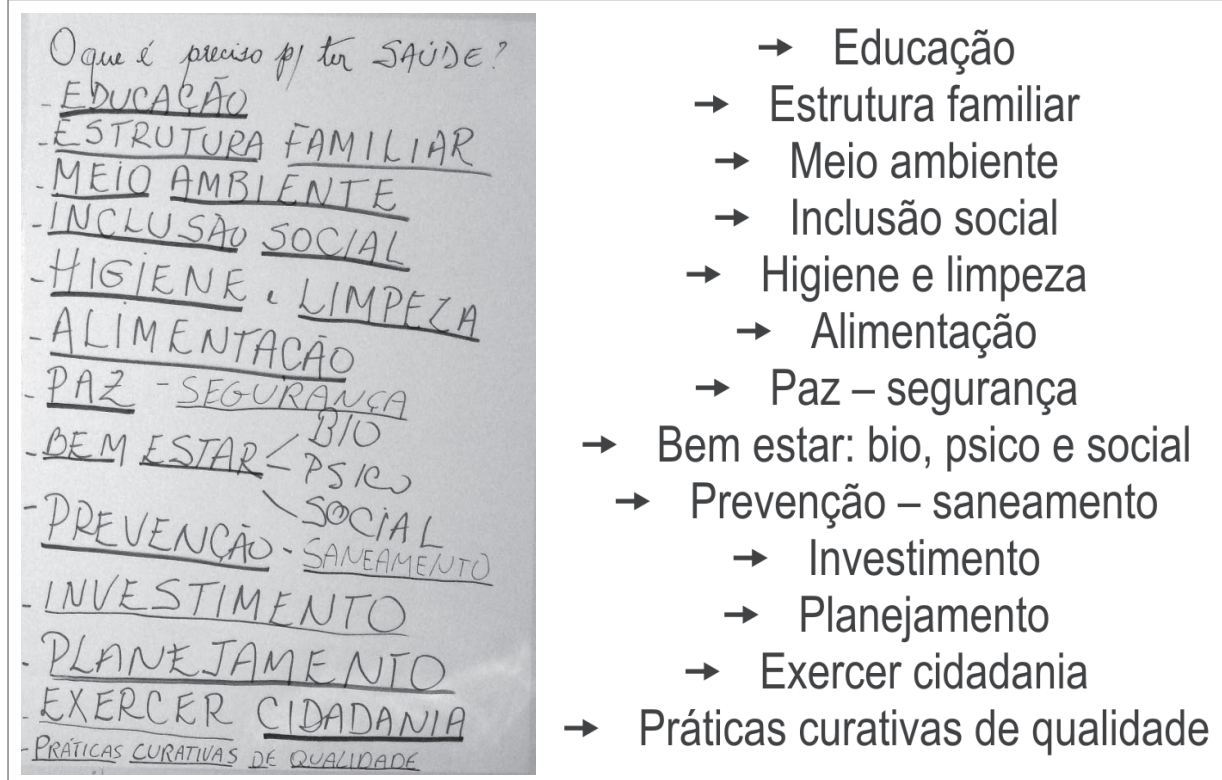

\section{Grupo de verbalização e grupo de observação (GVGO)}

As figuras 3 e 4 demonstram que o papel do conselho foi retratado corretamente, tendo sido colocados em questão alguns desafios para o exercício do controle social, entre os quais se destaca a necessidade de divulgação da existência, das discussões e decisões do conselho. Esta ausência de divulgação é criticada por Demo (1996), que acredita que a visibilidade dos Conselhos de Saúde é um ponto decisivo e se caracteriza pela transparência das ações, na criação de canais de comunicação com a população. Segundo o autor, o conhecimento coloca o usuário no centro do processo, numa relação de corresponsabilidade, e para que essa gestão participativa se concretize, torna-se necessário a existência de canais de participação desimpedidos e fluxo constante de informações.

Por isso, tornam-se importante os canais de comunicação e instrumentos que possibilitem a democratização da informação, como boletins informativos, cartilhas, jornais, entre outros, garantindo maior transparência das açôes dos Conselhos (ASSIS; VILLA, 2003). A informação e comunicação são fatores essenciais para construção e implementação de um sistema de saúde 
básico, principalmente quando ele objetiva fortalecer a participação popular, reconhecendo sua importância no campo do controle social (MORAES, 2006).

A informação possui uma dimensão política e estratégica para os processos decisórios nos Conselhos de Saúde, fazendo-se necessária a existência de mecanismos participativos e democráticos. $\mathrm{O}$ acesso às informaçōes precisa ser democratizado e as barreiras existentes superadas, para que o aparato que envolve a informação em saúde esteja a serviço dos sujeitos políticos (SILVA et al., 2007).

Segundo Silva et al. (2007), o acesso à informação amplia a capacidade de argumentação dos sujeitos políticos coletivos nos processos decisórios e implica a possibilidade de os Conselhos de Saúde deliberarem sobre a política de informação e comunicação em saúde e intervir na realidade hoje existente. Portanto, a ausência de comunicação entre os membros integrantes do CMS e a população assistida tem como resultante a desinformação, deixando os segundos à mercê das decisões de quem nem sempre sabe que mudanças devem ser tomadas (ALVES et al.,1998).

\section{Figura 3. Cartaz do Grupo 1: "O papel do Conselho de Saúde na participação e controle social”. Viçosa-MG (2007)}

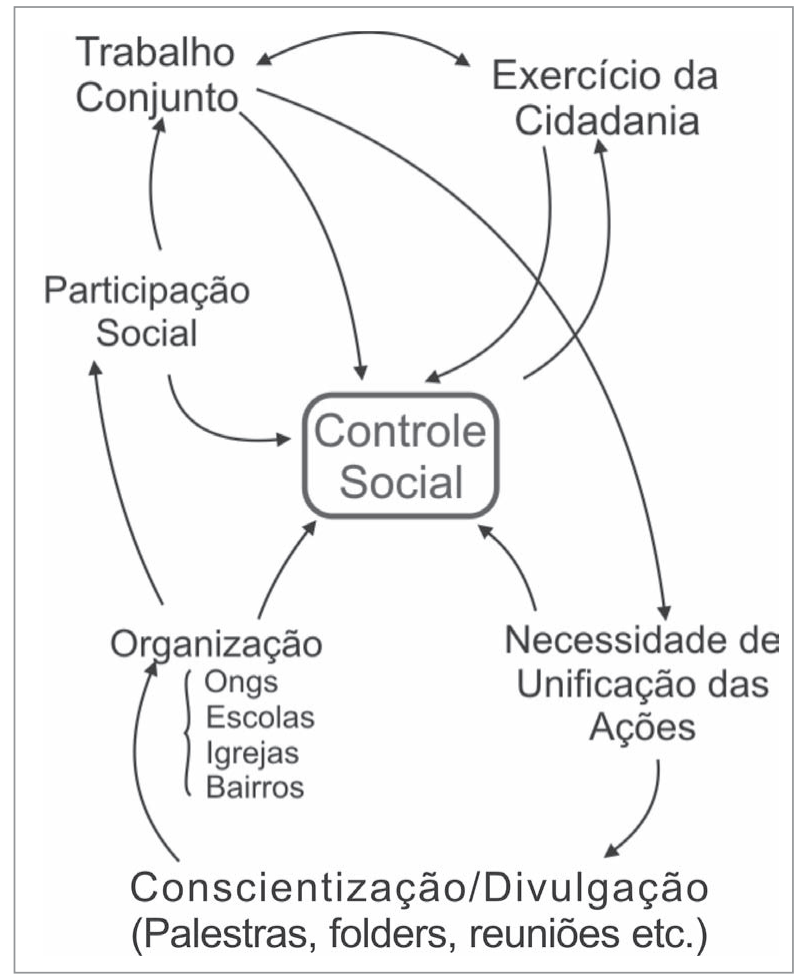


$\rightarrow$ A população conhece o CMS?

$\rightarrow$ A população reconhece o CMS?

$\rightarrow$ Maior interação com a comunidade.

$\rightarrow$ Comunicação por meio da mídia local.

$\rightarrow$ Dotação orçamentária.

$\rightarrow$ Democratização do CMS.

$\rightarrow$ Avaliação $\overline{\mathrm{IDH}}$

Indicadores

$\rightarrow$ Acompanhamento.

\section{Estudo dirigido}

As figuras 5 e 6 apresentam os pontos negativos que dificultavam o funcionamento do CMS segundo a opinião dos conselheiros. Dentre estes, destaca-se "falta de conhecimento da população da existência do CMS" e "falta de visibilidade e conhecimento do CMS e suas funções" relatados pelos grupos 1 e 2, respectivamente. Lopes e Almeida (apud SOARES; TRINCAUS, 2007) também identificaram entre as dificuldades para o funcionamento do conselho a falta da participação da população e dos funcionários nas atividades desenvolvidas e nas reunióes.

Durante a realização desta dinâmica, percebeu-se que nem todos os participantes conheciam o Regimento Interno do Conselho Municipal de Viçosa. Entretanto, alguns conselheiros evidenciaram o não-cumprimento de alguns itens das normas de funcionamento definidas em regimento próprio, tais como presente no Art. $9^{\circ}$, inciso IX, que define o papel duplo de conselheiro representante de um segmento e de formulação e deliberação coletiva no órgão colegiado, e incisos X e XI, que definem a importância da justificativa de ausência do titular à Secretaria Executiva e a comunicação ao suplente imediatamente, em tempo hábil para que o substitua na reunião. 
Segundo Assis e Villa (2003), uma das condições essenciais para a legitimidade do controle social é a organizacidade. Entre os fatores que a constituem, está o Regimento Interno do conselho. Para o autor, os conselheiros devem se orientar por este instrumento para os processos de discussão, regularidade das reuniōes, votação e outros encaminhamentos próprios das atividades dos conselheiros.

Em relação à regularidade nas reuniões, nossos achados vão ao encontro dos resultados do estudo de Morita et al.(2006), ao verificarem que algumas representações estariam no CMS apenas para ocupar uma vaga e fazer com que o conselho funcionasse adequadamente de acordo com as diretrizes do SUS - ou seja, alguns conselheiros constam como membros do conselho, mas, na realidade, nunca compareceram às reunióes.

Outro ponto negativo relatado que complementa a ausência física dos conselheiros para dificultar o funcionamento do CMS é a falta de embasamento e análise para a votação e a participação efetiva dos suplentes. Alguns conselheiros, embora presentes em praticamente todas as reuniōes, quase nunca se manifestam para debater o assunto ou para propor alguma sugestão - simplesmente chegam, sentam, acompanham a reunião e erguem o braço para votar e vão embora (MORITA et al., 2006). De acordo com Gerschman (2004), esta questão reflete a falta de conhecimento técnico especializado sobre o setor saúde que possibilite aos conselheiros discutirem os assuntos apresentados pelo presidente do Conselho.

Figura 5. Cartaz do Grupo 1: "Pontos negativos que dificultam o funcionamento do Conselho Municipal de Saúde”. Viçosa-MG (2007)

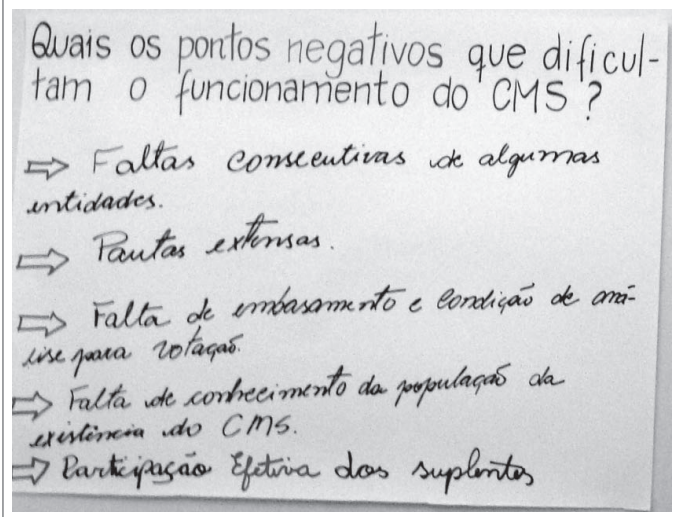

$\rightarrow$ Faltas consecutivas de algumas entidades.

$\rightarrow$ Pautas extensas.

$\rightarrow$ Falta de embasamento e condições de análise para votação.

$\rightarrow$ Falta de conhecimento da população da existência do CMS.

$\rightarrow$ Participação efetiva dos suplentes. 


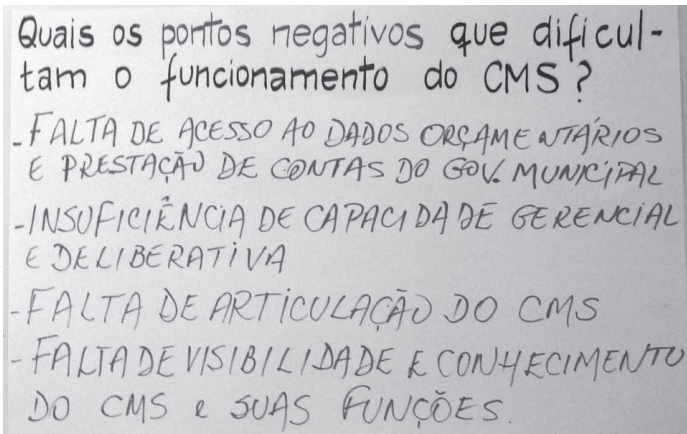

$\rightarrow \quad$ Falta de acesso aos dados orçamentários e prestação de contas do governo municipal.

$\rightarrow$ Insuficiência de capacidade gerencial e deliberativa.

$\rightarrow$ Falta de articulação do CMS.

$\rightarrow$ Falta de visibilidade e conhecimento do CMS e suas funções.

As figuras 7 e 8 apresentam as perspectivas esperadas pelo atual CMS, demonstrando que os participantes percebem um distanciamento entre o previsto pela normas de funcionamento e o que é realizado na prática, corroborando Kleba et al. (2007), que verificaram esforço excessivo em debates e decisões pontuais e focalizadas nas reuniões do Conselho Municipal de Saúde.

Outra perspectiva relatada é a maior articulação do conselheiro com suas bases. De acordo com o sanitarista Antônio Ivo (2007), o aumento do vínculo com suas bases é o que permite legitimar os conselheiros como representantes da sociedade para acumular mais força política e obter mais voz.

Alves et al. (1998) também defendem uma representatividade maior dos conselheiros. Segundo eles, o SUS só vai se consolidar quando o controle social for presente, eficaz, efetivo, esclarecido, fiscalizador, definidor e voltado para o coletivo, não para o individual. Esses autores sugerem ainda que, ao serem informados sobre o tema da reunião plenária seguinte, os conselheiros promovam o debate com os segmentos que representam para tirar uma posição coletiva e então iriam ao plenário para defendê-la, e não para serem conselheiros de si próprios. Retornariam ainda ao seu segmento e prestariam contas do que conseguiram aprovar ou não, seria um trabalho de mão-dupla, democratizando as decisões.

A capacitação dos conselheiros parece viabilizar a solução deste problema, pois, como mostrado neste estudo, os próprios conselheiros perceberam este fator como uma perspectiva, ou seja, algo ainda não realizado. De acordo com o observado no estudo de Correia (2005), os conselheiros capacitados apresentam 
uma média mais elevada de intervenções nas reuniōes e de articulação com sua base, do que os conselheiros não capacitados.

Figura 7. Cartaz do Grupo 1: "Perspectivas esperadas pelo atual Conselho Municipal de Saúde”. Viçosa-MG (2007)

$\rightarrow$ Cumprimento do Art.9, inciso IX. (página 5).

$\rightarrow$ Tirar uma estrutura mínima de pauta para a reunião seguinte.

$\rightarrow$ Comissões : - Organização das comissões

- Representação das comissões

$\ulcorner$ enviar a pauta

\section{Sequência $\Rightarrow$ CMS motivar}

Conscientizar a participação dos

suplentes nas reuniões do Conselho

$\rightarrow$ Continuidade das "capacitações".

Figura 8. Cartaz do Grupo 2: "Perspectivas esperadas pelo atual Conselho Municipal de Saúde”. Viçosa-MG (2007)

$\rightarrow$ Conselho atuante.

$\rightarrow$ Cumprir as competências do Regimento Interno com responsabilidade social.

$\rightarrow$ Articular-se com a comunidade e demais instituições representativas.

$\rightarrow$ Articulação do conselheiro com os seus pares.

As figuras 9 e 10 expressam as principais dificuldades esperadas para a gestão do conselho. Dificuldades derivam também de questôes regulamentares que afetam o resultado das resoluções adotadas. Por exemplo, evitar que o gestor imponha suas propostas, manipule as reuniōes ou desacate as decisóes deliberadas no colegiado. A isso se soma a complexidade dos assuntos discutidos, em particular os financeiros, sobre os quais as pessoas leigas não têm conhecimento. Isto tem levado a diversas iniciativas de capacitação de conselheiros que, junto com uma espécie de "profissionalização" dos representantes dos usuários, possibilitada pela sucessiva eleição ou indicação dos mesmos indivíduos, têm permitido que 
adquiram alguma familiaridade com as matérias relativas a políticas, programas, ações e serviços de saúde (LABRA; FIGUEIREDO, 2002).

Outra dificuldade esperada pelos conselheiros é a falta de participação do conselho na elaboração do Plano Municipal de Saúde (PMS). Mottin (1999) encontrou em seu estudo que a maioria das referências feitas pelos Secretários de Saúde entrevistados sugeriu situação de baixa participação do CMS, meramente formal, com justificativas que recaíram principalmente na questão do tempo reduzido para o preparo do PMS e a precária e passiva participação dos conselheiros em seu município.

Figura 9. Cartaz do Grupo 1: "Problemas que podem acontecer na atual gestão do Conselho Municipal de Saúde”. Viçosa-MG (2007)

$\rightarrow$ Esclarecimento sobre a eleição do presidente e vice-presidente.

$\rightarrow$ Participação formal dos conselheiros (voto sem embasamento, sem consciência específica de uma determinada questão).

\section{aprofundamento}

Figura 10. Cartaz do Grupo 2: "Problemas que podem acontecer na atual gestão do Consellho Municipal de Saúde”. Viçosa-MG (2007)

$\rightarrow$ Mobilização da comunidade: dificuldade

$\rightarrow \quad$ Não cumprimento das metas estabelecidas nas Conferências

$\rightarrow$ Não formulação do Plano Municipal de Saúde

\section{Considerações finais}

A metodologia participativa e a utilização de estratégias que privilegiaram a sistematização do conteúdo, assim como a reflexão sobre os referenciais teóricos apresentados e a participação a partir da correlação dos temas com as experiências práticas, foram fundamentais para ampliar e aprofundar o processo de empoderamento dos conselheiros. O curso permitiu o amadurecimento do papel do Conselho e dos conselheiros, instigando a necessidade de buscar informações e 
trocar experiências, o que pode ser demonstrado pela forte adesão e envolvimento

dos participantes em todos os momentos do curso. Além disso, o referencial teórico abordado subsidiou o desenvolvimento de competências para a participação da vida em sociedade e contribuiu para o pensamento reflexivo e crítico que qualifica a ação política e promove o empoderamento dos conselheiros, aplicando o controle social como ferramenta democrática para fazer valer o direito à saúde.

Entretanto, a capacitação permanente e continuada dos conselheiros ainda é um desafio a ser trabalhado, para que eles possam intervir efetivamente no fortalecimento do controle social, de forma coerente com os princípios e diretrizes do SUS, melhorando a qualidade dos serviços e a vida de todos os cidadãos. Desta forma, a capacitação dos conselheiros de saúde aparece como uma possibilidade de superação das dificuldades de implementação das conquistas legais, transformando esses atores sociais em protagonistas na construção de um sistema de saúde universal e equitativo.

\section{Referências}

ALVES, P.C. et al. A experiência da esquistossomose e os desafios da mobilização comunitária. Cadernos de Saúde Pública, Rio de Janeiro, v. 14, s.2, p. 79-90, 1998.

ASSIS, M.M.A.; VILLA, T.C.S. O Controle Social e a Democratização da Informação: Um processo em construção. Rev. Latino-americana Enfermagem, Ribeirão Preto, v. 11, n. 3, p. 376-382, 2003.

BORDENAVE, J.; PEREIRA, A. Estratégias de ensino-aprendizagem. 26aa ed. Petrópolis: Vozes, 2004.

BORDENAVE, J.E.D. Alguns fatores pedagógicos. In: SANTANA, J.P.; CASTRO, J.L. (Org.). Capacitação em Desenvolvimento de Recursos Humanos - CADRHU. Natal: EdUFRN, 1999.p. 261-268.

BOSI, M.L.M.; MERCADO, F.J. Pesquisa qualitativa de serviços de saúde. Petrópolis: Vozes, 2004.

BOURSE, C. On the distinction between Disease and Illness. Philosophy and Public Affairs, v. 5 , p. $49-68,1975$.

BRASIL. Ministério da Saúde. Para entender a Gestão do SUS. Brasília: Ministério da Saúde, 2003.

CALlahAN, D. The WHO definition of health. Stud Hastings Center, v. 1, n. 3, 1973.

CARVALHO, S.R. Os múltiplos sentidos da categoria "empowerment" no projeto de Promoção à Saúde. Cadernos de Saúde Pública, Rio de Janeiro, v. 20, n. 4, p. 1088-1095, 2004. 
CELEDON, C.; NOÉ, M. Reformas del sector de la salud y participación social. Revista Panamericana de Salud Pública, v.8, v. 1-2, p.99-104, 2000.

CORREIA, M.V.C. Desafios para o controle social: subsídios para capacitação de conselheiros de saúde. Rio de Janeiro: Ed. Fiocruz, 2005. 278p.

CORTES, S.M.V. Construindo a possibilidade da participação dos usuários: Conselhos e Conferências no Sistema Único de Saúde. Sociologias, Porto Alegre, n. 7, p. 18-49, 2002.

CUNHA, S.S. O controle social e seus instrumentos. Disponível em: <http://www.adm. ufba.br/capitalsocial/Documentos $\% 20$ para $\% 20$ download/Controle $\% 20$ Social $\% 20 \mathrm{e} \% 20$ Seus\%20Instrumentos.pdf >. Acesso em: 27 mai. 2008.

CYRINO, E.G.; TORALLES-PEREIRA, M.L. Trabalhando com estratégias de ensinoaprendizado por descoberta na área da saúde: a problematização e a aprendizagem baseada em problemas. Cad. Saúde Pública, Rio de Janeiro. v. 20, n. 3, p. 780-788, 2004.

DEMO, P. Participação é conquista. Noções de Política Social Participativa. Fortaleza: Imprensa Universitária da UFCE, 1996.

FERRAZ, M.S.F.C. O conceito de saúde. Rev. de Saúde Pública, v. 31, n. 5, p. 538-542, 1997.

FREIRE, P. Pedagogia da autonomia: saberes necessários à prática educativa. São Paulo: Paz e Terra, 2007.

GERSCHMAN, S. Conselhos Municipais de Saúde: atuação e representação das comunidades populares. Cad. Saúde Pública, Rio de Janeiro, v. 20, n. 6, p. 1670-81, 2004.

GUIZARDI, F. L.; PINHEIRO, R. Dilemas culturais, sociais e políticos da participação dos movimentos sociais nos Conselhos de Saúde. Ciência \& Saúde Coletiva, v. 11, n. 3, p. 797-805, 2006.

IMAGINÁRIO, L. et al. Um ensaio do balanço de competências em Portugal. Lisboa: MTS, 1998. IVO, A. A gestão autoritária cede espaço, pouco a pouco, à práxis democrática. Radis, Rio de Janeiro, n. 53, p. 12-19, jan. 2007.

KLEBA, M.E.; COMERLATTO, D.; COLliSElLI, L. Promoção do empoderamento com Conselhos Gestores de um Polo de Educação Permanente em saúde. Texto Contexto Enfermagem, Florianópolis, v. 16, n. 2, p. 335-42, 2007.

LABRA, M.E.; FIGUEIREDO, J.S.A. Associativismo, participação e cultura cívica. O potencial dos conselhos de saúde. Rev. Ciência \& Saúde Coletiva, São Paulo, v. 7, n.3, p. 537-547, 2002.

MARTINS, P.C. Controle social no Sistema Único de Saúde: análise da participação social e empoderamento da população usuária do sistema sanitário. 2007. 118p. Dissertação (Mestrado em Saúde Pública) - Departamento de Nutrição e Saúde, Universidade Federal de Viçosa, Viçosa, 2007. 
MENDES, E.V. Uma agenda para a saúde. São Paulo: Hucitec, 2006.

MITRE, S.M. et al. Metodologias ativas de ensino-aprendizagem na formação profissional em saúde: debates atuais. Ciência \& Saúde Coletiva, v. 13, sup. 2, p. 2133-2144, 2008.

MORAES, R.A. Cartas. Radis, Rio de Janeiro, n. 45, p. 4-5, maio 2006.

MORITA, I.; GUIMARÃES, J.F.C.; MUZIO, B.P. A participação de conselheiros municipais de saúde: solução que se transformou em problema?. Saúde e Sociedade, v. 15, n. 1, p. 49-57, 2006.

MOTTIN, L. M. Elaboração do Plano Municipal de Saúde: desafio para o município. Um estudo no Rio Grande do Sul. 1999. 159p. Dissertação (Mestrado em Saúde Coletiva) Fundação Oswaldo Cruz, Escola Nacional de Saúde Pública, Rio de Janeiro, 1999.

ORGANIZAÇÃO PAN-AMERICANA DA SAÚDE. Rede Interagencial de Informações para a Saúde. Indicadores básicos de saúde no Brasil: conceitos e aplicações. Brasília, DF: RIPSA, 2002, 300p.

RICHARDSON, R.J. et al. Pesquisa social: métodos e técnicas. São Paulo: Atlas, 1999.

SILVA, A.X.; CRUZ, E.A.; MELO, V. A importância estratégica da informação em saúde para o exercício do controle social. Ciência \& Saúde Coletiva, Rio de Janeiro, v. 12, n. 3, p. 683-688, 2007.

SOARES do BEM, A. A centralidade dos movimentos sociais na articulação entre o estado e a sociedade brasileira nos séculos XIX e XX. Educ. Soc., Campinas, v. 27, n. 97, p. 1137-1157, set./dez. 2006. Disponível em: <http://www.cedes.unicamp.br>. Acesso em: 28 jun. 2008. SOARES, L.G.; TRINCAUS, M.R. Participação e controle social: uma revisão bibliográfica dos avanços e desafios vivenciados pelos conselhos de saúde. Rev. Eletrônica Lato Sensu, n. 1, p. 245-264, 2007.

TURANO, W.; ALMEIDA, C.C.C. Métodos e técnicas aplicados à educação nutricional. In: GOUVEIA, E.L.C. Nutrição, saúde \& comunidade. 2 ed. Rio de Janeiro: Revinter, 1999. p. 107-135. Cap. 5.

VAZQUEZ, M.L. et al. Los procesos de reforma y la participación social en salud en América Latina. Gaceta Sanitaria, v. 16, n. 1, p. 30-38, 2002.

WENDHAUSEN, A.; CAPONI, S. O diálogo e a participação em um conselho de saúde em Santa Catarina, Brasil. Cadernos de Saúde Pública, Rio de Janeiro, v. 18, n. 6, p. 16211628, 2002.

WENDHAUSEN, A.L.P.; BARBOSA, T.M.; BORBA, M.C. Empoderamento e recursos para a participação em conselhos gestores. Saúde e Sociedade, v. 15, n. 3, p. 131-144, 2006. 
Social control in the Unified Health System: subsidies to build health counselors' skills This paper discusses the experience of the training course for health counselors in the city of Viçosa, Minas Gerais State, from the perspective of awareness of the conscious exercise of social control, thus enabling the construction of a more fair and equitable health system, according to the ideal of the movement of the Brazilian health reform. We perform a qualitative approach on the dynamics presented in the course, which is based on the methodology of active teaching and learning. The participatory methodology and use of strategies that focused on the systematization of content, as well as the reflection on the theoretical frameworks presented from the correlation of topics with practical experiences were essential to broaden and deepen the process of empowerment of the counselors. As a result, it was possible to identify some challenges for the exercise of social control, such as the importance of active participation and the need to seek information and exchange experiences. Thus, it is emphasized that the participation of health counselors in training workshops appears as a possibility of overcoming the difficulties of implementing legal achievements, the awareness of these social actors to implement the position of mere passive spectators into protagonists in the construction of a universal and equitable health care system.

Key words: counsellors' training, social participation, health board, social control, active approach. 